\title{
Prevalence and factors associated with postpartum use of long-acting reversible contraception in Bukombe District, Geita Region, Tanzania: a community- based study
}

Kiondo Solomon Kiondo', Eusebious Maro ${ }^{1,2}$, Sophia Kiwango ${ }^{1}$, Julius Pius Alloyce ${ }^{2}$, Benjamin C. Shayo ${ }^{1,2}$ and Michael Johnson Mahande ${ }^{1,3^{*}}$

\begin{abstract}
Background: Globally, approximately half of all pregnancies occur before 24 months after child birth. In Sub Saharan Africa the unmet need for family planning is highest among postpartum women. There is a dearth of information regarding factors associated with postpartum use of long acting reversible contraception (LARC) in Tanzania particularly in the Lake zone. This study aimed to determine the prevalence and factors associated with postpartum use of LARC (<24 months) in Bukombe District, Geita Region in the Lake zone, in 2018.

Methodology: Community based analytical cross-sectional study was conducted between May and June 2018 among women with less than 24 months since delivery. Multistage sampling technique was used to recruit participants. Face to face interviews with 768 postpartum women was conducted using standardized questionnaire. Data were analyzed using Stata Version 13.0. Multivariable logistic regression model was used to determine factors associated with postpartum use of LARC.

Results: Prevalence of postpartum use of LARC was 10.4\%. Urban residence (AOR $=2.94,95 \%$ Cl: 1.07-8.06), having formal employment ( $\mathrm{AOR}=4.81,95 \% \mathrm{Cl}: 1.85-12.57)$ and receiving family planning counseling ( $\mathrm{AOR}=4.39,95 \% \mathrm{Cl}$ : 1.89-10.20) were significantly associated with postpartum LARC use.

Conclusion: The postpartum use of LARC was low in the studied population with implants being the most commonly used method. Urban residency, formal employment and receiving family planning counseling were associated with postpartum LARC use. Improving prenatal and quality of family planning counseling is warranted to increase postpartum LARC utilization in Bukombe.
\end{abstract}

Keywords: Long-acting reversible contraception, Postpartum, Determinants, Tanzania

\footnotetext{
* Correspondence: jmmahande@gmail.com

IKilimanjaro Christian Medical University College, Moshi, Tanzania

${ }^{3}$ Department of Epidemiology and Biostatistics, Institute of Public Health,

Kilimanjaro Christian Medical University College, Moshi, Tanzania

Full list of author information is available at the end of the article
}

C C The Author(s). 2020 Open Access This article is licensed under a Creative Commons Attribution 4.0 International License, which permits use, sharing, adaptation, distribution and reproduction in any medium or format, as long as you give appropriate credit to the original author(s) and the source, provide a link to the Creative Commons licence, and indicate if changes were made. The images or other third party material in this article are included in the article's Creative Commons licence, unless indicated otherwise in a credit line to the material. If material is not included in the article's Creative Commons licence and your intended use is not permitted by statutory regulation or exceeds the permitted use, you will need to obtain permission directly from the copyright holder. To view a copy of this licence, visit http://creativecommons.org/licenses/by/4.0/ The Creative Commons Public Domain Dedication waiver (http://creativecommons.org/publicdomain/zero/1.0/) applies to the data made available in this article, unless otherwise stated in a credit line to the data. 


\section{Introduction}

Postpartum Family Planning (PPFP) is defined as the prevention of unintended pregnancy and closely spaced pregnancies through the first 12 months post-delivery [1]. Postpartum women have highest unmet need for family planning which increases their risk for mistimed and unintended pregnancies [1]. PPFP help couples to space pregnancies and achieve desired family size [1]. Postpartum contraceptives options include: short term methods such as condoms, injectables, oral contraceptives pills (OCP), long acting reversible contraception (LARC) [which includes subdermal implants and intrauterine devices (IUDs)], where as permanent methods include vasectomy and female sterilization [2].

LARC can avert early unplanned pregnancies during an extended postpartum period better than any other contraceptions [2]. LARC has been reported to be as much as 20 times more effective than oral contraceptions, transdermal patches and vaginal rings [3], with a failure rate of 1 per 100 [2]. It is most effective than any form of contraception, cost effective, long-lasting and convenient [2].

Finding fromDemographic and Health Surveys from 27 countries revealed that $95 \%$ of women within 12 months postpartum needed to prevent pregnancy in the next 24 months after birth, but majority $(70 \%)$ of these women were not using contraception [4]. This reflects high unmet need for postpartum contraception among this high risk group. Findings from 21 low-and middle-income countries (LMICS) regarding pregnancy risk and postpartum contraceptive method use showed that, $61 \%$ of postpartum women who were within 24 months postpartum had an unmet need for modern contraceptives [5]. Moreover, in LMICS less than $15 \%$ of postpartum women use LARC [6] but majority $(50-96 \%)$ of them relies on use of short acting contraceptives which are less effective in preventing unwanted pregnancies [5].

Majority (61\%) of women in Tanzania have been reported to have unmet needs for family planning within 2 years postpartum, with only $31 \%$ were using the family planning methods [7]. Again, family planning method mix shows that only $10 \%$ of the women reported using highly effective methods including long acting reversible contraceptives [5] while $1 \%$ and $7 \%$ of the women of reproductive age reported using IUDs and implants respectively [8]. As a consequences of high unmet need for modern contraceptives during this period, $36 \%$ of pregnancies are unwanted [9] and $19 \%$ of all births have short birth intervals, with nearly half (47\%) of all pregnancies occurring within recommended optimal interpregnancy interval [24 months] [8]. In addition Tanzania has maternal mortality ratio of 556/100,000 per live birth, which is unacceptably high [8]. Geita region has $35 \%$ unmet need for modern contraceptives among all women of reproductive age with total fertility rate (TFR) of $5.5 \%$; these figures are above the national estimates of $22 \%$ and 5.2 for unmet need for FP and total fertility rate respectively [8].

Despite the fact that Geita region has the highest unmet need for modern contraceptives use in the country, little has been documented about factors influencing postpartum family planning use particularly long acting reversible contraceptives in this region. In addition there is paucity of data in postpartum family planning use in Tanzania, coupled with low utilization of LARC methods.

Different studies in the literature have shown predictors of postpartum LARC use such as occupation [10], secondary or tertiary education [11], high parity [12] and mode of delivery [13]. This study aimed to determine the prevalence and factors associated with postpartum use of long acting reversible contraceptives ( $<24$ months) in Bukombe District, Geita Region in the Lake zone.

\section{Methods and materials Study design and settings}

A community-based analytical cross sectional study was conducted from May to June 2018, in Bukombe District, Geita region. Bukombe district has 3 divisions, 17 wards, 52 villages and 184 sub-villages, and it has an estimated population of 224,542. Of these, $19.1 \%$ comprise Women of reproductive age [15-49]. Bukombe district is among the districts with highest population growth rate and birth rates in Tanzania (5.9\% and 4.6\% respectively) [14]. The main source of income generating activities include; agriculture, animal husbandry, gold mining, petty business and formal sector employment.

The district has one hospital and two health centers which are government-owned. There are also fifteen, dispensaries where by six belong to the government and the remaining nine belongs to private sector. Only ten [10] healthcare facilities in this district provide family planning services.

\section{Study population, sample size and sampling techniques}

This study included postpartum women [15-49 years] who were less than 24 months post-delivery from nine villages in Bukombe District. We estimated the sample size using single population proportion formula taking in consideration the following assumptions; standard deviation of 1.96 corresponding to $95 \%$ confidence interval (CI), proportion of 13 [8], marginal error of $3.5 \%$ and design effect of 2 . After adding $10 \%$ for non-response rate the, estimated sample size was 780 postpartum women. However during the field work we could recruit 768 postpartum women.

Multi-stage sampling technique was used to obtain 768 postpartum women. The $1^{\text {st }}$ stage involved purposeful selection of 2 out of 3 divisions based on their large population size. The $2^{\text {nd }}$ stage involved selection of 3 wards after stratification of wards from 2 division into rural and urban, 
using proportion to size, 1 ward from urban settings and 2 wards from rural settings were selected. The $3^{\text {rd }}$ stage involved selection of 9 villages whereby in each ward 3 villages were randomly selected. At the lowest level of local administration in Bukombe district (hamlets), 3 hamlets were randomly selected in each of selected villages and postpartum mothers who were less than 24 months since delivery at the time of data collection were identified through door to door approach with the help of local leaders and those who fulfilled study inclusion criteria were invited to participate in our study.

\section{Study variables}

The dependent variable in this study was use of long acting reversible contraceptives (Implants and IUD) during postpartum period and independent variable were sociodemographic characteristics (Age, marital status, education level, residence, occupation, income per month and Partner's level of education), others were reproductive characteristics (Number of living children, mode of index delivery, place of index delivery, menstrual resumption, duration of postpartum period, counseling on FP and discussing FP use with the partner).

\section{Data collection methods and quality assurance}

Due to the sensitive nature of this study, we used only female research assistants who were medical doctors in data collection process. All our research assistants were trained on key technical terminologies used in data collection tool as well as research ethical issues. Face to face interviews were used to collect data using structured questionnaires which was adopted from Tanzania Demographic health survey with slight modification to suit for cultural context. Information on sociodemographic characteristics, reproductive health characteristics, contraceptives use and contraceptive preference as well as children status. Principle investigator visited field sites frequently to supervise data collection activities and field staff convened with the principle investigator during the evenings to counter-check completeness of data captured before submission to data server.

\section{Data analysis}

Data were coded, entered, cleaned and transferred to Stata Version 13.0 for the analysis purposes. Descriptive statistics were summarized using proportion for categorical data, means, standard deviation (SD) median and interquartile range (IQR) for numerical data. Multivariable logistic regression model was used to determine odds ratio and 95\% confidence intervals for factors associated with postpartum LARC use. A p-value of less than $5 \%$ was considered statistically significant.

\section{Results}

Socio-demographic Characteristics of the participants

A total of 768 women within 24 months postpartum were invited to participate in this study, whereby all agreed and were enrolled into the study, making a 100\% response rate. Two participants were excluded in the analysis due to incomplete information. The mean age of respondents was $26.9 \pm 6.7 \mathrm{SD}$ years. Majority, [652 (85.1\%)], of participants were married, [714 (93.2\%)] had primary education/below while at least two thirds were residents of rural areas. Regarding partners' characteristics, [557 (86.2\%)] of participants' partners had primary education (Table 1).

\section{Reproductive characteristics of the participants}

The median number of living children was 3 (IQR: 25). With regard to number of living children, slightly higher than two fifth [336 (43.9\%)] of the postpartum women had 1-2 children. In the current delivery, most of the participants [735 (96\%)] had vaginal delivery and nearly half [371 $(48.4 \%)]$ of the postpartum women had delivered at home. Nearly two-thirds [428 (58.5\%)] of

Table 1 Socio-demographic Characteristics of study participants $(N=766)$

\begin{tabular}{|c|c|c|}
\hline Variables & $\mathbf{n}$ & $\%$ \\
\hline \multicolumn{3}{|l|}{ Age, years } \\
\hline $15-24$ & 326 & 42.6 \\
\hline $25-34$ & 318 & 41.5 \\
\hline $35-49$ & 122 & 15.9 \\
\hline Age $^{a}$ & $(26.9 ; 6.7)$ & \\
\hline \multicolumn{3}{|l|}{ Marital status } \\
\hline Married & 652 & 85.1 \\
\hline Unmarried & 114 & 14.9 \\
\hline \multicolumn{3}{|l|}{ Level of education } \\
\hline Primary/below & 714 & 93.2 \\
\hline Secondary/above & 52 & 6.8 \\
\hline \multicolumn{3}{|l|}{ Occupation } \\
\hline Unemployed & 740 & 96.6 \\
\hline Employed & 26 & 3.4 \\
\hline \multicolumn{3}{|c|}{ Estimated income per month (Tsh) } \\
\hline$<100,000$ & 618 & 80.7 \\
\hline$>100,000$ & 148 & 19.3 \\
\hline \multicolumn{3}{|l|}{ Residence } \\
\hline Rural & 523 & 68.3 \\
\hline Urban & 243 & 31.7 \\
\hline \multicolumn{3}{|c|}{ Partner's level of education $(n=731)^{b}$} \\
\hline Primary/below & 557 & 86.2 \\
\hline Secondary and above & 174 & 23.8 \\
\hline
\end{tabular}


participants reported to discuss family planning issues with their partners, whereas, at least half of the participants [425 (55.5\%)] had menstrual resumption (Tables 2 and 3).

\section{Prevalence of LARC use among postpartum women} Of the 766 postpartum women, 80 were using LARC, corresponding to a prevalence of $10.4 \%$. Only eight percent reported to be using short methods, (Fig. 1). The most frequently used contraceptive methods were implants 76 (53.9\%) and injectables 37 (26.2\%). Other methods such as hormonal pills $13(9.2 \%)$, condoms $11(7.8 \%)$ and intrauterine devices 4 (2.8\%) were infrequently used, (Fig. 2).

\section{Socio-demographic and reproductive characteristics associated with postpartum LARC use}

Bivariate and multivariable logistic regression models were used to identify factors associated with postpartum LARC use. Bivariate analyses showed that, women with secondary education or above had two fold higher odds of LARC

Table 2 Reproductive characteristics of the study participants $(N=766)$

\begin{tabular}{|c|c|c|}
\hline Variable & $\mathbf{n}$ & $\%$ \\
\hline \multicolumn{3}{|l|}{ Living children } \\
\hline $1-2$ & 336 & 43.9 \\
\hline $3-4$ & 228 & 29.8 \\
\hline $5+$ & 202 & 26.4 \\
\hline Median (IQR) & $3[2-5]$ & \\
\hline \multicolumn{3}{|c|}{ Mode of index delivery } \\
\hline Vaginal delivery & 735 & 96.0 \\
\hline Caesarean delivery & 31 & 4.0 \\
\hline \multicolumn{3}{|c|}{ Place of index delivery } \\
\hline Home & 371 & 48.4 \\
\hline Health facility & 395 & 51.6 \\
\hline \multicolumn{3}{|c|}{ Discuss FP with partner $(n=731)^{a}$} \\
\hline No & 303 & 41.5 \\
\hline Yes & 428 & 58.5 \\
\hline \multicolumn{3}{|l|}{ Menstrual resumption } \\
\hline No & 341 & 44.5 \\
\hline Yes & 425 & 55.5 \\
\hline \multicolumn{3}{|c|}{ Duration of postpartum period (months) } \\
\hline$<6$ & 241 & 31.5 \\
\hline $6-12$ & 270 & 35.2 \\
\hline$>12-<24$ & 255 & 33.3 \\
\hline \multicolumn{3}{|c|}{ Counseled on FP $(n=141)^{b}$} \\
\hline No & 57 & 40.4 \\
\hline Yes & 84 & 59.6 \\
\hline
\end{tabular}

Notes: ${ }^{a}$ Those with partners; ${ }^{\mathrm{b}} n=141$ variable limited to users only " were you councelled on family planning methods before starting using current method" Abbreviations: FP Family planning, IQR Interquantile range use compared to their counterparts with primary/below education $(\mathrm{COR}=2.37$, 95\% CI:1.05-4.57), women with formal employment were almost five times more likely to use LARC compared to those who were unemployed $(\mathrm{COR}=4.99,95 \% \mathrm{CI}: 2.12-11.72)$. Women who reported to reside in urban had 4 -folds $(\mathrm{COR}=3.78,(95 \% \mathrm{CI})$ : 2.32-6.15) higher odds of using LARC compared with their rural counterparts. In addition, partners education level, partner 's occupation, couples discussion about FP, mode of delivery, place of delivery during the index pregnancy, menstrual resumption, postpartum duration and counseling on FP-methods were also significantly associated with postpartum LARC use.

Variables which showed significance in the bivariate analysis and those with $\mathrm{p}$ value less than 0.25 were selected and included in the multivariable analysis to control for possible confounders on LARC use. The multivariable logistic regression model showed that postpartum women who were residents of urban areas and those who had formal employment were almost three times more $(\mathrm{AOR}=$ 2.94, 95\% CI: $1.07-8.06)$ and five times more (AOR $=4.82$, 95\% CI: 1.85-12.57) likely to use postpartum LARC compared to their counterparts, respectively. Furthermore, postpartum women who were counseled on FP methods were four times more $(\mathrm{AOR}=4.39,95 \% \mathrm{CI}$ : $1.89-10.20$ ) likely to use LARC than those who were not counseled about FP use.

\section{Discussion}

In this study, we found the prevalence of postpartum use of LARC methods was as low as $10.4 \%$. Factors such as mother's occupation, mother's residence and being counseled on family planning use were important predictors for postpartum use of LARC.

The prevalence of postpartum LARC use estimated in our study is consistent with the national average estimate of $10 \%$ [8]. The similarity between these findings could be explained by comparability in population characteristics studied, as majority of women prefer short methods of contraceptive than the LARC. The present finding is also in congruent with previous studies conducted within and outside Africa. For example, in a community based study in rural Uganda by Anguzu et al., the authors reported the postpartum LARC prevalence of $8.5 \%$, [12]. Similar finding was also reported in rural China where the authors reported postpartum LARC prevalence of $9.9 \%$ [13]. In contrast, higher prevalence of postpartum LARC use $(34.3 \%)$ has been reported in Ethiopia [15], Kenya (38.3\%) [16] and Ethiopia (36.7\%), [17]. The possible reasons for difference in findings between our study and Ethiopian studies could be due to nature of the studied population. Our population was mainly rural while participants in the Ethiopian studies were mainly from urban area where majority of 
Table 3 Factors associated with postpartum LARC use, Multivariable analysis ( $N=766)$

\begin{tabular}{|c|c|c|c|c|c|}
\hline \multirow[t]{2}{*}{ Variable } & \multicolumn{2}{|c|}{ LARC use } & \multirow[t]{2}{*}{ COR $(95 \% \mathrm{Cl})$} & \multirow[t]{2}{*}{ AOR $(95 \% \mathrm{Cl})$} & \multirow{2}{*}{$\begin{array}{l}P \text { - } \\
\text { value }\end{array}$} \\
\hline & No & Yes n (\%) & & & \\
\hline \multicolumn{6}{|l|}{ Sociodemographics } \\
\hline \multicolumn{6}{|l|}{ Age (years) } \\
\hline $15-24$ & 326 & $33(10.1)$ & 1 & & \\
\hline $25-34$ & 318 & $39(12.3)$ & $1.24(0.76-2.03)$ & $0.76(0.28-2.07)$ & 0.592 \\
\hline $35-49$ & 122 & $8(6.6)$ & $0.62(0.28-1.39)$ & $0.40(0.08-1.98)$ & 0.261 \\
\hline \multicolumn{6}{|l|}{ Marital status } \\
\hline Married & 652 & $63(9.7)$ & 1 & & \\
\hline Unmarried & 114 & $17(14.9)$ & $1.64(0.92-2.92)$ & $0.85(0.25-2.81)$ & 0.785 \\
\hline \multicolumn{6}{|l|}{ maternal education } \\
\hline Primary/below & 714 & $70(9.8)$ & 1 & & \\
\hline Secondary/ above & 52 & $10(19.2)$ & $2.19(1.05-4.57)$ & $0.82(0.20-3.33)$ & 0.784 \\
\hline \multicolumn{6}{|l|}{ Occupation } \\
\hline Unemployed & 740 & $71(9.6)$ & 1 & & \\
\hline Employed & 26 & $9(34.6)$ & $4.99(2.12-11.72)$ & $4.82(1.85-12.57)$ & 0.0004 \\
\hline \multicolumn{6}{|l|}{ Income per month } \\
\hline$<100,000$ & 618 & $65(10.5)$ & 1 & & \\
\hline$>100,000$ & 148 & $15(10.1)$ & $0.96(0.53-1.74)$ & $0.59(0.22-1.57)$ & 0.290 \\
\hline \multicolumn{6}{|l|}{ Residence } \\
\hline Rural & 523 & $32(6.1)$ & 1 & & \\
\hline Urban & 243 & $48(19.8)$ & $3.78(2.32-6.15)$ & $2.94(1.07-8.06)$ & 0.036 \\
\hline \multicolumn{6}{|c|}{ Partner's education $(n=731)$} \\
\hline Primary/below & 557 & $48(8.6)$ & 1 & & \\
\hline Secondary and above & 174 & $27(15.5)$ & $1.95(1.17-3.24)$ & $1.81(0.69-4.73)$ & 0.226 \\
\hline
\end{tabular}

\section{Reproductive factors}

Discussing FP with partner $(n=731)$

$\begin{array}{ll}\text { No } & 303 \\ \text { Yes } & 428\end{array}$

Living children

$1-2$

3-4

$5+$

Mode of index delivery

Vaginal delivery

C/S delivery

Place of index delivery

$$
\begin{aligned}
& \text { Home } \\
& \text { Health facility }
\end{aligned}
$$

\section{Menstrual resumption}

No

Yes

341

425

\section{Postpartum period}

$<6$ months

6-12 months

241

270
$5(1.7)$

$70(16.4)$

$36(10.7)$

$28(12.3)$

$16(7.9)$

$71(9.7)$

9 (29.0)

18 (4.9)

$62(15.7)$

$16(4.7)$

$64(15.1)$

$17(7.1)$

$17(6.3)$
$11.65(4.51-30.08)$

$3.23(0.8412 .41)$

0.088

$1.17(0.69-1.97)$

$1.45(0.51-4.11)$

0.489

$1.13(0.39-1.33)$

$0.79(0.20-3.03)$

0.727

$3.82(1.68-8.67)$

$2.12(0.32-14.12)$

0.435

$3.65(2.09-6.36)$

$0.59(0.21-1.64)$

0.314

$21.71(2.02-6.41)$

$0.61(0.21-1.81)$

0.375
$0.74(0.20-2.73)$

0.654 
Table 3 Factors associated with postpartum LARC use, Multivariable analysis ( $N=766)$ (Continued)

\begin{tabular}{|c|c|c|c|c|c|}
\hline \multirow[t]{2}{*}{ Variable } & \multicolumn{2}{|c|}{ LARC use } & \multirow[t]{2}{*}{ COR $(95 \% \mathrm{Cl})$} & \multirow[t]{2}{*}{ AOR $(95 \% \mathrm{Cl})$} & \multirow{2}{*}{$\begin{array}{l}P \text { - } \\
\text { value }\end{array}$} \\
\hline & No & Yes n (\%) & & & \\
\hline$>12-<24$ months & 255 & $46(18.0)$ & $2.9(1.60-5.26)$ & $0.98(0.31-3.13)$ & 0.973 \\
\hline \multicolumn{6}{|c|}{ Counseled on FP $(n=141)$} \\
\hline No & 57 & $20(35.16)$ & 1 & & \\
\hline Yes & 84 & $60(71.4)$ & $4.63(2.13-10.05)$ & $4.39(1.89-10.20)$ & 0.001 \\
\hline
\end{tabular}

COR Crude odds ratio, AOR Adjusted odds ratio, CI Confidence interval

women have access to information regarding the importance of FP including LARC. However, this also could be due to the fact that most of the health facilities in previous studies have high health services coverages including family planning services [17]. The difference between our study and the Kenyan counterparts could be due to the fact that, the Kenya study was a hospital based study which might provide women with better access to information regarding reproductive and sexual education including FP as compared to women in the present study whose majority (68\%) were rural dwellers with poor contact with the health care providers especially those from the pastoral communities whereby nearly $50 \%$ of postpartum mothers reported to have had home delivery in during their index delivery.

In the present study, most (82\%) of postpartum women were not using any form of modern contraceptives during 2 years post-delivery. Consequently this predisposes a large proportion of women in the studied communities to unplanned pregnancies, short interpregnancy intervals and their associated complications. Planning and spacing of children especially with the use of modern contraceptives especially LARC is important for the general wellbeing of the family and community at large.

In this study, majority of mothers who reported to be using LARC, were using hormonal implants. Our findings form a concordance with the national estimate which revealed that only $7 \%$ and $1 \%$ of the women of reproductive age use hormonal implants and IUDs, respectively [8]. Likewise, previous studies in Ethiopia $[11,17]$ and Kenya [18] showed observed that majority of women reported using hormonal implants. Findings from 12 countries in sub-Saharan African including Tanzania reported that hormonal implants were the first or second most widely used in 10 out of 12 countries studied compared with IUDs, pills and injectables [19]. The low use of IUDs could be explained by perceived misconceptions such as fear of abdomen pain, discomfort during sex and myth that IUDs can move into the abdomen during sexual intercourse [20]. Our finding is in contrast with previous study in rural China where the authors found that majority reported using IUDs than implants [13].

In this study, urban residence was an important predictor for postpartum LARC use. Postpartum women in the urban settings were more likely to use LARC as compared to their rural counterparts. This finding is consistent with previous studies conducted in northwest Ethiopia [21]. The possible explanation could be that postpartum women in urban areas have been reported to have better access to information regarding family planning and general reproductive and sexual health matters than women who reside in rural setting with poor health services [22]. This might be the case for the

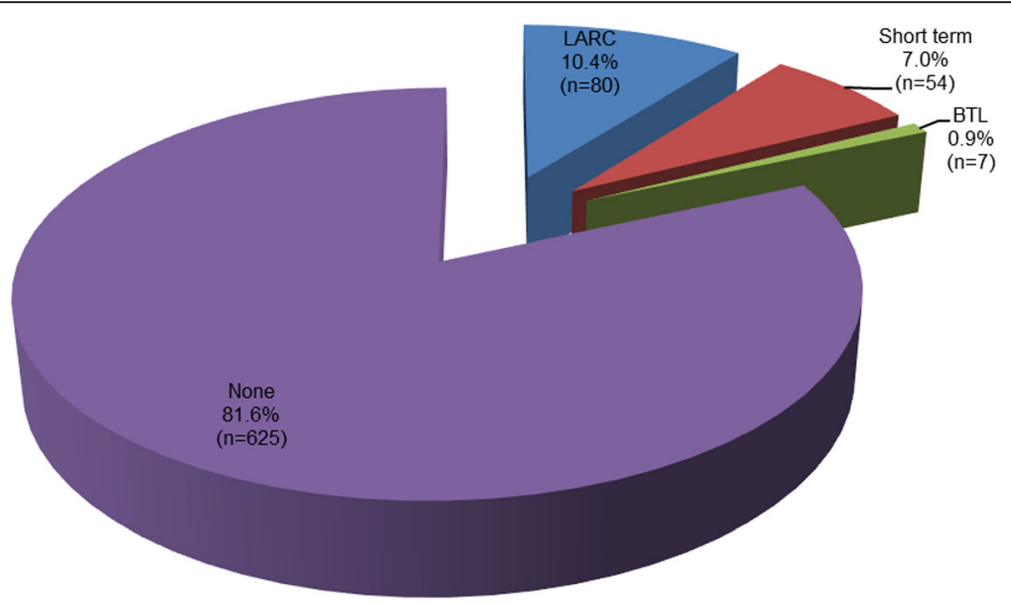

Fig. 1 Prevalence of modern contraceptives use by method type among postpartum women 


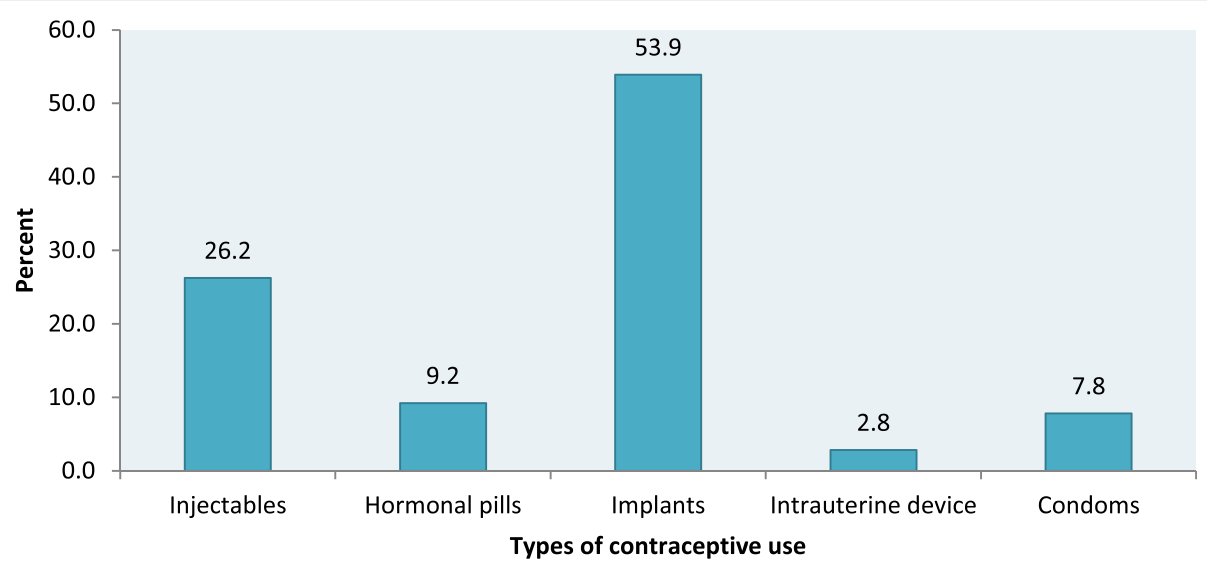

Fig. 2 Types of Modern contraceptives used by postpartum women

women in the studied population. Our findings imply that postpartum family planning services are no different, therefore there is a need for more efforts to increase utilization of modern family planning use among women in rural areas.

We also established that the occupation of the postpartum mother was associated with LARC use, particularly the formal employment. Similar relationship was reported among Kenyan women [16]. This could be explained by the fact that women with formal employment are more likely to be knowledgeable and well informed on family planning matters, have higher desire for fertility control and possibly have better access to family planning services.

Postpartum family planning counseling increased women's likelihood of using LARC methods. Even though current study didn ' $t$ assess the timing of family planning counseling, but previous studies in Ethiopia [17] and Thailand [23] revealed that contraceptive counseling was associated with an increased LARC use especially when done during immediate postpartum period. Previous authors also have demonstrated that, anticipatory counseling regarding side effects and bleeding profile can help in improving acceptability and continuation rate to postpartum contraceptive use [24]. Therefore, this should be offered upon initiation of contraceptive method.

\section{Study limitations}

The study design was a cross-section in nature which make difficult to establish the causal effect relationship. This study was done in a district where majority belong to the pastoral communities, this limit the generalization of findings whole country, but may reflect the situation in similar settings.

\section{Conclusion}

The postpartum use of LARC was low in the studied population with implants being the most commonly used method. Postpartum women from urban residence, with formal employment, and who were counseled about LARC were more likely to use LARC.

Our finding highlights the importance of family planning counseling, particularly client should be empowered with knowledge to make informed choice, to understand common side effects of LARC and should understand the management of side effects in case needs arises. Quality counseling will help to dispel community myths and misconception towards LARC method which will help to scale up the utilization of postpartum family planning. Furthermore we call for more efforts to increase LARC use in rural areas.

\section{Abbreviations}

AOR: Adjusted odds ratio; COR: Crude odds ratio; Cl: Confidence Interval; CRERC: College Research Ethics and Review Committee; DELTAS: Developing Excellence in Leadership, Training and Science; IQR: Median and interquartile range; IUDs: Intrauterine devices; FP: Family Planning; LMICS: Low—and middle-income countries; LARC: Long acting reversible contraception; PPFP: Postpartum Family Planning; OCP: Oral contraceptives pills:

SD: Standard deviation

\section{Acknowledgements}

Our sincere gratitude goes to research assistants, participants, Geita Regional medical officer, Bukombe District Medical officer and local village leaders. Lastly, we would like to appreciate Endulen. eV of Germany and MoHCDGEC for studies Scholarship at KCMUCo.

\section{Author' contributions}

KSK, MJM: designed the study, participated in data collection and played part in manuscript writing. EM: participated in study design and manuscript writing. SK and BCS participated in manuscript writing. JPA: performed statistical analysis. All authors read and approved the manuscript.

\section{Funding}

This work was supported through the DELTAS Africa Initiative grant \# DEL15-011 to THRiVE-2. The DELTAS Africa Initiative is an independent funding scheme of the African Academy of Sciences (AAS)'s Alliance for Accelerating Excellence in Science in Africa (AESA) and supported by the New Partnership for Africa's Development Planning and Coordinating Agency (NEPAD

Agency) with funding from the Welcome Trust grant \# 107742/Z/15/Z and the UK government. Other support were from Endulen. eV of Germany and MoHCDGEC. The views expressed in this publication are those of the author(s) and not necessarily those of AAS, NEPAD Agency, Welcome Trust or the UK government, Endulen. eV of Germany and MoHCDGEC. 


\section{Availability of data and materials}

The datasets from this study are readily available from the corresponding author when requested.

\section{Ethics approval and consent to participate}

Ethical approval for the study was obtained from Kilimanjaro Christian Medical College Research Ethics and Review Committee (CRERC). Permission to conduct the study was obtained from Regional Medical Officer, Bukombe District Medical Officer, wards, villages and the community involved in the study. Participants' confidentiality were maintained throughout the study period by using identification numbers instead of participant names. Verbal and written consent were also obtained from individual participants before recruitment for a study.

For participants aged less than 18 years old and married, parents/guardian provided consent and participant assented to participate in the study. Participation in our study was voluntarily, a participant had a right to withdraw from study at any time without even providing explanation.

\section{Consent for publication}

Permission to publish this work in international journals was obtained from the participants; during data collection every participant was informed that study findings will be published to add the body of knowledge on postpartum LARC use.

\section{Competing interests}

The authors declare that they have no competing interests. All authors read and approved the final manuscript.

\section{Author details}

${ }^{1}$ Kilimanjaro Christian Medical University College, Moshi, Tanzania. ${ }^{2}$ Department of Obstetrics and Gynecology, Kilimanjaro Christian Medical Centre, Moshi, Tanzania. ${ }^{3}$ Department of Epidemiology and Biostatistics, Institute of Public Health, Kilimanjaro Christian Medical University College, Moshi, Tanzania.

Received: 28 May 2020 Accepted: 8 September 2020

Published online: 11 December 2020

\section{References}

1. WHO. Programming Strategies for Postpartum Family Planning. Geneva: WHO Press; 2013.

2. RCOG. Best practice in postpartum family planning. 2015 [Cited 7 May 2020 ]. Available from: https://www.google.com/search?q=Best+practice+in+ postpartum+family+planning\%2C+rcog $+2015 \&$ oq $=$ Best + practice+in + postpartum+family+planning\%2C+rcog+2015\&aqs=chrome..69i57.106 88j0j7\&sourceid=chrome\&ie=UTF-8.

3. Winner B, Peipert JF, Zhao Q, Buckel C, Madden T, Allsworth JE, et al. Effectiveness of long-acting reversible contraception. N Engl J Med. 2012; 366(21):1998-2007

4. Ross JA, Winfrey WL. Contraceptive Use, Intention to Use and Unmet Need During the Extended Postpartum Period. International Family Planning Perspectives. 2001;27(1):20-7.

5. Moore Z, Pfitzer A, Gubin R, Charurat E, Elliott L, Croft T. Missed opportunities for family planning : an analysis of pregnancy risk and contraceptive method use among postpartum women in 21 low- and middle-income countries. Contraception. 2015;92(1):31-9.

6. Harrison MS, Goldenberg RL. Immediate postpartum use of long-acting reversible contraceptives in low- and middle-income countries. Maternal Health Neonatology Perinatology. 2017;3:24.

7. National Bureau of Statistics (NBS) [Tanzania] and ICF Macro. Tanzania Demographic and Health Survey 2010. Dar es Salaam: NBS and ICF Macro; 2011.

8. Ministry of Health, Community Development, Gender, Elderly and Children (MoHCDGEC) [Tanzania Mainland], Ministry of Health (MoH) [Zanzibar], National Bureau of Statistics (NBS), Office of the Chief Government Statistician (OCGS), and ICF 2016 Tanzania Demographic and Health Survey and Malaria Indicator Survey (TDHS MIS) 2015-16 Dar es Salaam Rockville MoHCDGEC, MoH, NBS, OCGS, and ICF.

9. Keogh SC, Urassa M, Kumogola Y, Kalongoji S, Kimaro D, Zaba B. Postpartum Contraception in Northern Tanzania: Patterns of Use, Relationship to Antenatal Intentions, and Impact of Antenatal Counseling. Stud FamPlann. 2015;46(4):405-22.
10. Chansin W, Jittima M, Wattanayingcharoenchai R, Aimjirakul K. Postpartum Use of Long-Acting Reversible Contraception in Primiparous Women: RamathibodiHospital' s Experiences. Thai J ObstetGynaecol. 2014;22(1):29-36.

11. Abraha TH, Teferra AS, Gelagay AA. Postpartum modern contraceptive use in northem Ethiopia: prevalence and associated factors. Epidemiol Health. 2017;39:201701.

12. Anguzu R, Sempeera $H$, Sekandi JN. High parity predicts use of long-acting reversible contraceptives in the extended postpartum period among women in rural Uganda. Contraception and Reproductive Medicine. 2018;3:6.

13. Kang C, Li P, Liu X, Ding Y, Wang X, Zhou H. Use of contraceptives and uptake of long-acting reversible contraception among postpartum women in rural China. BMJ Sex Reprod Health. 2018;0:1-6.

14. PO-RALG. Bukombe district councils strategic plan for the period of 2016 2021. Bukombe, Geita; 2016.

15. Gebremedhin AY, Kebede Y, Gelagay AA, Habitu YA. Family planning use and its associated factors among women in the extended postpartum period in Addis Ababa. Ethiopia Contraception and Reproductive Medicine. 2018;3:1.

16. Jalang'o R, Thuita F, Barasa SO, Njoroge P. Determinants of contraceptive use among postpartum women in a county hospital in rural KENYA. BMC Public Health. 2017;17:604.

17. Tamrie YE, Hanna EG, Argaw MD. Determinants of Long Acting Reversible Contraception Method Use among Mothers in Extended Postpartum Period, Durame Town, Southern Ethiopia : A Cross Sectional Community Based Survey. Health. 2015;7:1315-26.

18. Ontiri S, Ndirangu G, Kabue M, Biesma R, Stekelenburg J, Ouma C. Long-Acting Reversible Contraception Uptake and Associated Factors among Women of Reproductive Age in Rural Kenya. Int J Environ Res Public Health. 2019;16:1543.

19. Jacobstein R. Liftoff: The Blossoming of Contraceptive Implant Use in Africa. Global Health: Science and Practise. 2018;6(1):17-39.

20. Mwafulirwa T, Shea MSO, Hamela G, Samuel E, Chipangula V, Hosseinipour MC, et al. Family Planning Providers ' Experiences and Perceptions of Long Acting Reversible Contraception in Lilongwe. Malawi African Journal of Reproductive Health. 2016;20(2):62-71.

21. Mengesha ZB, Worku AG, Feleke SA. Contraceptive adoption in the extended postpartum period is low in Northwest Ethiopia. BMC Pregnancy and Childbirth. 2015;15:60.

22. Sultan S. The Effects of Education, Poverty, and Resources on Family Planning in Developing Countries Clinics in Mother and Child Health. Clinics Mother Child Health. 2018;15:289.

23. Kaewkiattikun K. Effects of immediate postpartum contraceptive counseling on long-acting reversible contraceptive use in adolescents. Adolescent Health Medicine and Therapeutics. 2017:8:115-23.

24. Villavicencio J, Allen RH. Unscheduled bleeding and contraceptive choice: increasing satisfaction and continuation rates. Open Access Journal of Contraception. 2016;7:43-52.

\section{Publisher's Note}

Springer Nature remains neutral with regard to jurisdictional claims in published maps and institutional affiliations.

Ready to submit your research? Choose BMC and benefit from:

- fast, convenient online submission

- thorough peer review by experienced researchers in your field

- rapid publication on acceptance

- support for research data, including large and complex data types

- gold Open Access which fosters wider collaboration and increased citations

- maximum visibility for your research: over $100 \mathrm{M}$ website views per year

At BMC, research is always in progress.

Learn more biomedcentral.com/submissions 